\section{Improving the reading comprehension of primary-school students at frustration- level reading through the paraphrasing strategy training: A multiple-probe design study}

ilhan İlter a

\begin{tabular}{ll}
\hline Received: & 06 February 2017 \\
Revised: $\quad 18$ August 2017 \\
Accepted: $\quad 08$ Sept. 2017 \\
ISSN: 1307-9298 \\
Copyright @ IEJEE \\
www.iejee.com
\end{tabular}

DOI: 10.26822/iejee.2017131894

\title{
Abstract
}

The purpose of this study was to investigate the effectiveness of "RAP" [RAP is a three-step strategy: Read-Ask-Put], a paraphrasing cognitive strategy training, associated with a self-regulatory model, on the development of reading comprehension among fourth-grade students. All participants were selected on the basis of initial reading comprehension measures and consisted of three male students who were identified as being at a frustration-level reading. A multiple-probe design across participants was used. As a result, the participants showed significant improvements in the text recall and an enhancement their reading comprehension skills. Two of the participants were able to maintain their improvements and generalized each step of the strategy in the "RAP" to different content-area texts. The remaining participant made remarkable improvements with respect to the baseline phase, but did not maintain and generalize the strategy. Suggestions were made for improving future research investigating the effects of RAP paraphrasing strategy.

Keywords: Reading comprehension, Cognitive strategy training, Paraphrasing, RAP paraphrasing strategy, Frustration-level readers

\section{Introduction}

Reading comprehension includes the complex cognitive processes that need to be used in conjunction with reading activity to provide readers the opportunity to understand the meaning from a reading material. As texts in schools becomes an essential source of knowledge, reading comprehension becomes increasingly important when students graduate from one grade to another. Reading practices are traditionally based on teacher based lecture, reading the texts in textbooks and answering teacher-directed questions (Smagorinsky, 2001; Toste, Fuchs \& Fuchs, 2013). However, students have to have effective reading skills that could provide them with the ability to access complex content presented in textbooks to be successful in general education classrooms. This is because today's youth is expected to have higher-level literacy skills than past generations to keep up with the demands of the business environment (Biancarosa \& Snow, 2006).

Essential strategies for reading comprehension include predicting the content, analyzing the text structure, identifying the main idea, and constructing summarizations. Identifying the main idea and details of a text is an essential ability for successful reading comprehension and is generally considered a prerequisite for higher-level strategies (Watson, Gable, Gear \& Hughes,
2012).

One of the more promising ways to improve metacognitive comprehension skills is cognitive strategy training with regard to reading. The idea behind this approach is that students can get the information about the content-area text materials when they are taught how and when to process it effectively. However, the strategic instruction model should focus on teaching students a set of specific strategies to actively gain knowledge and develop many work skills (Hagaman \& Reid, 2008). The strategic instruction model is an approach that focuses on teaching reader how to learn, learn how to apply what he/she learns during reading, and how to overcome reading difficulties and comprehension problems (Deshler \& Lenz, 1989; Schumaker, Deshler \& Ellis, 1986). A training provided to learners about reading strategies can be an effective way of helping them understand more of what they are reading of using their cognitive strategies during reading and making them aware of difficulties associated with constructing new meanings. However, some factors may prevent this. First, research in the field of reading strategies in general education classrooms has lagged far behind those on essential reading comprehension skills (Pressley \& McCormick, 1995; Williams, 2005). Second, it may be difficult to teach 
reading strategies that encourage independent performance from real-world events. Many effective teachers generally use strategy training in terms of how to use reading strategies effectively for their students in the classroom (Williams, 2002). Research has shown that teachers pay less attention to strategy training on reading in general education classrooms (Alfassi, 2004; Fordham, Wellman \& Sandmann, 2002; Ulusoy \& Dedeoğlu, 2011). For this reason, reading skills researchers have emphasized that teachers should continue to devote sufficient time to content learning and to adopting strategy training in their classes. In addition, they should develop practices based on a variety of experimental bases (Snyder \& Pressley, 1995).

There is a clear need for effective reading strategies for understanding texts that can be easily used in general education classrooms. Studies that investigate the effects of teaching students to learn reading skills through the strategic instruction model have shown that such an awareness facilitates reading comprehension in students at different reading levels (Hagaman \& Reid, 2008; Mastropieri, Scruggs \& Graetz, 2003; Shanahan \& Shanahan, 2008). This is important because researchers have pointed out that reading is a cognitive process that actively requires students to make new meanings and conclusions in texts by activating their background knowledge (Pressley, 2002; Rasinski, 2012). The purpose of this training is not just to learn a method in a simple way, but also to interpret knowledge that is taught by the proper use of a set of specific cognitive strategies. Therefore, strategic training on reading comprehension should be considered as a useful approach by students as it provides them with an opportunity to better understand and apply the information in the text, store it in memory, and allow them recall it (Deshler \& Lenz, 1989; Reid, Lienemann \& Hagaman, 2013). However, research on the development of reading comprehension has shown that the strategy training, for instance, causal questioning techniques, enhances children's inferential and comprehension skills (Van-den Broek, Kendeou, Lousberg \& Visser, 2011).

One of the reading strategies that is considered effective for students with different reading requirements is the self-regulating model. This model involves explicitly teaching students how to understand what they read to help them improve their comprehension of the content. Such an instructional approach involves teaching students to activate cognitive dialogues with texts, to generate inferential questions about the main ideas and supporting details in the texts, using complete original sentences (Berkeley, 2007). Self-regulation, by which students monitor, control and organize their own reading comprehension performance has shown promising results for students at different reading ability levels (Rosenshine, Meister \& Chapman, 1996). Hagaman and Reid (2008) argue that the use of a self-inquiry approach during reading help readers focus on key ideas and details in the text.

Several examples of planned teaching practices and activities based on the self-regulatory approach have shown that they improve comprehension skills in particular with regard to expository texts. Hagaman, Casey and Reid (2016) taught a paraphrasing strategy, entitled "RAP" [Read-Ask-Put] that is associated with the self-regulatory model to sixth-grade students. After training, it was observed that students showed significant improvements in their reading comprehension skills for expository texts as a result of the practice. In another study, Ellis and Graves (1990) concluded that teaching a subject through the paraphrasing strategy, RAP, improved the reading comprehension levels of 47 secondary-school students with learning difficulties. The RAP strategy is a meta-cognitive technique common to the strategic instruction model and allows the use of listening, thinking-aloud and reading comprehension skills to facilitate reading and reading comprehension. In RAP acronyms are taught to readers in order to activate their cognitive dialogues and to have them think about and use the three steps (i.e. Read a paragraph, Ask myself "What was the main idea and two details, and Put it into my own words) in a particular strategy. The RAP strategy serves such a purpose for students and teachers, but this acronym also helps remind students who use the strategy to continuously keep talking to the text while reading as a way to enhance their reading comprehension (Hagaman \& Reid, 2008; Katims \& Harris, 1997).

Teaching RAP Paraphrasing Strategy for Frustration-Level Readers

Paraphrasing is to help readers understand paraphrases in texts and provides students with the ability to obtain the targeted information to be taught and promotes the use of their complete sentences. Paraphrasing strategy is in the same category with some other strategies, such as developing a reading purpose, diversifying reading styles appropriate to the type of text, moving back and forth within the text to recall main ideas and details related to the reading material, making predictions about what the author/text will tell (Taraban, Rynearson \& Kerr, 2000). Teachers who want to teach the paraphrasing strategy in the RAP to ensure that students are aware of the main ideas and details in a text. In paraphrasing, students are encouraged to use their own words and phrasing to translate the text to their way telling it (Kletzien, 2009). Pressley (2002) noted a restatement of text or paraphrasing strategy in reading when describing the characteristics of an independent reader. According to Pressley, paraphrasing allows students to learn through reading, thinking-aloud the main ideas, solving problems, and completing a reading task without the teacher's support as a meta-cognitive strategy.

Paraphrasing requires readers to identify the main idea and to put the key details related to the main ideas in their own words in order to reduce the overall length of the paragraph. Therefore, it is suggested that paraphrasing should be taught to students before or during summarization (Watson et al., 2012). Reading skills researchers define the paraphrasing as a successful comprehension strategy that combines questioning, understanding, and summarizing skills (Schumaker, Denton \& Deschler, 1984 citied Katims \& Harris, 1997). However, research has indicated that students who engaged in strategies requiring a paraphrasing were 
more likely to comprehend main ideas and recall text (Best, Rowe, Ozuru, \& McNamara, 2005). Many students with reading difficulties are encountered in almost every school. It is necessary to determine the reading difficulties of these students and appropriate methods to enhance their reading skills. The individual who cannot learn to read does not achieve success in school, and this negatively affects the social relations and maturation of the individual (Dağ, 2010; Vassaf, 2003). It seems that many poor readers have difficulty while reading in a) having troubles in word recognition, b) making too much effort to understand when the words in the text are being read correctly, c) bringing together what they have read in a meaningful and appropriate whole when deciphering the words correctly and easily. The emergence of any of these leads to a sense of personal failure, feelings of being burdened by a frustrating reading experience, and inadequate reading comprehension (Rasinski, 2006).

The purpose of this study was to investigate the effects of RAP paraphrasing training as a cognitive strategy (Oxford, 1990) on the development of reading comprehension of fourth-grade students at a frustration-level reading. According to Qualitative Reading Intervention-5 (Leslie \& Caldwell, 2011), while students reading text at an independent-level are able to answer $90 \%$ of the comprehension questions correctly and they can recognize between 93 and $97 \%$ of the words, students reading at a frustration-level answer fewer than $70 \%$ of the questions correctly and can recognize fewer than 93\% of the words (Gickling \& Thompson, 1985). Frustration-level reading does not improve oral reading fluency and could lead to negative feelings about reading (Zutell \& Rasinski. 1991; Worthy \& Broaddus, 2001). It is notable that across both text genres and grade levels, frustration-level readers' average comprehension was poor (Rachel, Dickens \& Elizabeth Meisinger 2017). As students are increasingly to be found at frustration-level, these students may experience tension or exhibit negative body movements during reading (Halladay, 2012). Khun and Stalh (1998) suggest that poor readers cannot automatically comprehend the meaning of words from context because they are overly dependent on the text, which makes it difficult to understand what they read. Researchers have noted that reading difficulties in general education classrooms is due to lack of strategic reading instruction activities (Cavkaytar, 2010; Vacca, Vacca \& Mraz, 2011). According to Fordham et al. (2002) the reason of problems in reading comprehension in content-area classes is based on the fact that many teachers are unable to provide the necessary higher-level reading skills training to their students and that they do not include particular metacognitive reading strategies in their content-area practices. However, studies investigating the effectiveness of reading modality on reading comprehension have shown that poor readers can learn a variety of specific reading strategies through explicit instruction and use cognitive strategies to overcome their reading difficulties (IIter, 2017; Tomesen \& Aarnoutse, 1998). In sum, the earlier an intervention is made with regard to the problems of students with difficulties in reading, the more successful they will be. If the problem persists, it will become a habit and the academic success, psychological, social and affective development of the student will be negatively affected (Dağ, 2010). This present study thus aimed to teach the RAP paraphrasing strategy to support the reading comprehension skills of primary school students identified as the frustration-level readers through the use of multiple-probes. As a result of a literature review, it was found that there have been limited research on the RAP paraphrasing strategy training program for students with reading difficulties. The study replicated and extended the previous studies (e.g. Dickens \& Meisinger, 2016; Hagaman et al. 2016; Katims \& Harris, 1997) by investigating whether or not fourth-grade students at a frustration-level reading were able to accurately comprehend expository texts during reading while controlling for reading skill. In addition, it emphasized the importance of cognitive strategy training to help frustration-level readers to maximize learning performance.

\section{Method}

\section{Research Design and Participants}

The effect of the RAP strategy training associated with a modified version of the strategic instruction model (Ellis, Deshler, Lenz, Schumaker \& Clark, 1991; Schumaker et al.1986) on the development of reading comprehension of the students at frustration-level reading was investigated. A multiple-probe design across participants was used (Tekin-iftar \& Kırcaali-iftar, 2016). The effectiveness of teaching RAP strategy on reading comprehension was assessed through following probes in the form of baseline, independent performance, maintenance, and generalization. The participants consisted of fourth-grade students in a primary-school in a socio-economically low-level school located in Bayburt Province, Turkey. The participants in this grade were selected from 21 students, 12 boys and 9 girls. Three criteria were used in the selection of the participants. First, specifically for accelerated readers were not included in the current study. To meet this criterion, a 30item cloze test procedure involving an informal reading inventory was used to assess the participants' reading level rates (McKenna \& Stahl, 2009). The test including 30 blanks which were formed as the fifth word of each sentence, starting from the second sentence was extracted, and the first and the last sentences were given exactly the same as in the test (Ulusoy, 2009). The cloze text consisted of an expository social studies text at grade-level. Jennings, Caldwell and Lerner (2006) indicates that expository texts are often denser conceptually, less personal, contain more unfamiliar vocabulary and technical terminology require more background knowledge, and are often above the ability of frustrationlevel readers. The participants' reading comprehension rates that correspond to independent, instructional, and frustration reading were assessed by considering an informal reading inventory procedure. In this reading inventory procedure, a score of $60 \%$ or higher indicates that the text can be understood completely by the students. They may be able to read the material on their own without guidance. A score of $40 \%$ to $59 \%$ indicates that the text can be read with some competency by 
students. These students can be identified as instructional-level readers. A score below $40 \%$ indicates that the text is probably too difficult for the students (Vacca \&Vacca, 2008, p.60). They will need either a great deal of reading guidance to benefit from the materiel, or more suitable material. Researchers have argued that informal reading inventories, such as cloze test procedures have received wide acceptance among teachers and clinicians, and are recognized as valuable instruments in reading assessment (e.g. comprehension, word reading accuracy, reliance on context in word recognition) (Dağ, 2010; Johns, 1988 citied Rasinski, 1999; Şahindokuyucu, 2006).

The administration time for the cloze test was 50 minutes. The test-retest reliability of the cloze test was .91. The cloze test results showed that six students in this class scored higher than $60 \%$ and 9 students' scores ranged from $40 \%$ to $59 \%$. Five students scored below $40 \%$ in the cloze test. The scores of this last group of students ranged from $17.01 \%$ to $38.21 \%$. According to the results, the students who scored $60 \%$ or higher were at an independent-level reading, the students with a score between $40 \%$ and $59 \%$ were at an instructional-level reading and the students with a score below $40 \%$ were readers at the frustration-level reading (Akyol, 2011; McKenna \& Stahl, 2009; Macdonald-Ross \& Scott, 1995).

In relation to cloze procedures, McLeod and Anderson (1970) developed a cloze test in which students used comprehension and decoding skills to determine missing words in a text. The test allowed the teacher to assess a whole class at once. They suggested that reading level could be accurately identified by the use of cloze reading assessment. However, some popular alternatives for evaluating reading comprehension abilities include cloze tests as a standardized reading comprehension measure (Grant, 1978; Vacca \& Vacca, 2008). Researchers have noted that it is appropriate for use in assessing and designing reading comprehension questions that will give a valid picture of comprehension on a variety of levels (Rubin, 2011). Hence, the use of a cloze test is suggested generally for supporting readers who struggle with reading comprehension and word recognition (Akyol, 2011; Palumbo \& Loiacono, 2009). The process involves providing the right words to fill deletions in a text passage and requires students to make sense of syntax, as well as semantics (Rubin, 2011).

The second criterion was that the participants should score below $40 \%$ in the cloze test to for participation in this study. As the RAP strategy is only intended to help students with reading difficulties in the understanding of expository texts, 5 students who were identified as being at a frustration-level reading made up the sample of this study. In terms of the third criterion, the investigator conducted interviews with the participants' teacher to check whether or not the students were at a frustrationlevel, and to gather some demographics before the possible participants were included in the RAP strategy training. The teacher was presented with the names of these participants and their scores from the cloze test. Given the teacher's comments, 2 of the 5 participants were not at a frustration-level reading. Rather these students deemed to be at an instructional-level reading. The teacher reported that the rest of the students had reading difficulties and problems while reading expository texts within the content of various activities. When the teacher was asked what kinds of reading difficulties they had, the teacher informed the investigator that those students had difficulties in making logical conclusions from a text they had read, lacked reading skills such as being able to identify a main idea, comprehending problems with establishing cause-effect relationships, and interpreting and summarizing texts. The teacher confirmed this by documenting the low grades of those students during quizzes and artifact examples undertaken in the past.

The range of cloze scores of the two participants identified were reviewed in consideration of their teacher's views. They scored below $40 \%$, which was a reading comprehension rate at the instructional-level reading. These students were excluded from the study. The remaining three participants were not found to have any learning disabilities in the school records. In sum, for this study was concluded that these students were at a frustration-level reading (Vacca \& Vacca, 2008). After this step, the investigator interviewed the participants' parents with school management guidance to ensure their approval. During the interviews, the investigator shared his expertise with the parents, and then informed them about the sub-research of the present study and presented the documents for the proposed intervention. As a result, the strategy training program began after getting written approval from the parents of the participants. In order to provide internal validity with regard to the participants' reading level for the treatment control purposes it was ensured that there was no reading training presented to the participants in their school within the dates when the research would be administered. However, the participants' names were hidden and code names were used for ethical reasons. The first participant was given the code name Murat, the second participant Mahmut and the third participant Vedat. The participants' demographics and scores with regard to the reading assessment were presented in Table 1.

\section{Dependent and Independent Variables}

The dependent variable was the development level of the participants' reading comprehension. The participants' level of success in reading comprehension was accepted by using the three steps of the RAP strategy as recalling the main idea and details of the expository texts. Reading comprehension behaviors were defined as; a) Thinking of the content by looking at the title and sub-title of a text, b) Reading each paragraph of a text, c) Putting the main ideas and two details of the paragraph using his/her own words using complete sentences and d) Following the instructions of the implementer. The independent variable was teaching the "RAP paraphrasing strategy" to the participants to develop an understanding of expository texts. The application of the independent variable was presented in the intervention sessions under the title of the treatment process. The independent variable was administered by organizing two intervention 
sessions per week over two days involving one-to-one teaching. Data were collected at each session.

Table 1. The participant demographics by their achievement status in reading

\begin{tabular}{llccc}
\hline Participant & Gender & Special Education & $\begin{array}{c}\text { Cloze Test Percent Correct } \\
<\mathbf{4 0 \%}\end{array}$ & $\begin{array}{c}\text { Age } \\
\text { Murat }\end{array}$ \\
Mahmut & Male & - & $21.45 \%$ & 11 \\
Vedat & Male & - & $17.91 \%$ & 10 \\
& Male & - & $26.47 \%$ & 10 \\
\hline
\end{tabular}

\section{Note $=$ A score below $40 \%$ indicates that the text is probably too difficult for students at frustration-level reading}

\section{The Implementers}

The implementation of this study was carried out with the investigator (the author) as an instructor. The instructor was an assistant professor with 12 years' experience in higher education and $\mathrm{K}-12$ school. The instructor has conducted studies on teachers' reading practices and vocabulary instruction in general education classes. In addition, a research assistant and a teacher were recruited to participate on a volunteer basis in this study. The research assistant had a PhD degree in primary-school education with a professional interest in reading practices. The teacher was a graduate of the primary-school teacher education program and had 12 years of experience. The teacher had worked for 5 years in the school in which the study was conducted. All the educators had already received a theoretical and practical training on reading education.

\section{Intervention Environment, Time and Materials}

The intervention sessions were held in the specialeducation teaching classroom (15 square meters, 3 tables, 1 computer, 1 chalkboard, 3 chairs) in the participants' school. The instructor, the research assistant and the participant's teacher participated in the strategy intervention. Sessions were arranged according to the teachers' leisure hours and outside the participant's class hours. This ensured that the participant was able to participate seamlessly in all sessions. A timekeeper, a prize board, various expository social studies and science text passages at grade-level, a RAP poster and blank RAP cards and crayons were used during the sessions. 15 short-expository texts used in all the sessions were selected from fourth-grade social studies and science textbooks (Kurt, 2016; McGuire, 2013; Ministry of National Education, 2016a-2016b; Westfall, 2005). The length of the texts ranged from 100 to 200 words.

\section{Short-Answer Questions}

Short-answer questions were used to assess the effectiveness of the steps of the RAP strategy training on progress with regard to the development of the participants' reading comprehension. In order to develop the short-answer questions, the investigator selected a variety of expository text passages appropriate to the RAP procedure. The instructor developed two types of shortanswer questions, taking into account the most important information in each passage in order to assess the participants' reading comprehension progress. The first took the form of explicit questions about text passages, and the second was implicit questions about the text. The text-explicit questions pertaining to the text passages were questions involving recall, of what was clearly in the text (Hagaman \& Reid, 2008). The text-implicit questions about the text were in the form of comprehension questions involving overall understanding. These required students to infer or figure out information from the text (e.g., why are greenhouse gases increasing? Because when they are burned to be converted into energy, petroleum, coal and fossil fuels and release a great amount of carbon dioxide, methane and water vapor emissions). Correct responses to both the implicit and explicit-text questions pertaining to the expository text passages were directly related to information in the text, not from previously learned information. The participants were asked to answer in writing the 10 short-answer questions tied to the expository text passages. They were not informed of a correct or incorrect answer. The instructor gathered the participants' responses directly onto a scoring sheet that including both the questions and the required responses. The number of correct responses was represented by the proportion of correct responses to the 10 short-answer questions. An independent reliability rater who was blind to the current study and who possessed a doctorate in the field of education was asked to submit a copy of the participants' answers given to the short-answer questions. Interrater agreement (Reliability $=$ Agreements $/$ [Agreements + Disagreements] $x$ 100) between the rater and the investigator (Miles \& Huberman, 1994; Tekin \& KırcaaliIftar, 2016) was found to be $.92 \%$.

\section{Percentage of Text Recall}

Another way used to assess the participants' reading comprehension skills was to determine the percentage of a text recall (the main ideas and key details). This method was developed by Hagaman and Reid (2008) and involved readers retelling or writing a list of important ideas and key details for each paragraph in a text (Leslie \& Caldwell, 2001). To ensure that the participants could read the texts 
fluently in all probes and intervention sessions, the participants' teachers were interviewed, and then five short-expository texts (approximately 150-280 wordslengths) at grade-level were selected. The number of main ideas in each text varied between 3 and 5 . The number of key details was between 8 and 10. The participants were asked to put the main ideas and details of the text in all probes. The participants were not expected or required to recall the exact words used in the text. It was acceptable for the participants in text what they read (Hagaman, Casey \& Reid, 2012; Hagaman \& Reid, 2008). All the text information recall was converted to a percentage graphically. In the baseline, independent performance and maintenance probes, the expository social studies texts were given to the participants, while the expository science texts were used with regard to the generalization probes. The participants were asked to read the texts silently. After reading, each participant was asked to write the main ideas and details they could recall in the text which they had just read. The participants received points for the main ideas and details recalled from the given text. The percentage of text-recall was calculated separately for the total number of the main ideas and key details.

\section{Social Validity}

The participants were interviewed to assess the social validity of the intervention of the RAP strategy training at the end of the treatment (Wolf, 1978). A self-report satisfaction form that had been developed was used for each participant. The participants were asked independently to rate seven questions regarding the effectiveness and the, usefulness of the strategy training on a scale [The RAP strategy training effectiveness a) $5=$ Most helpful and 1= Least helpful; The use of the strategy b) 4 = Always; 3 = Frequently; 2 = Sometimes; 1 = Never; The strategy satisfaction c) $4=$ Very effective; $3=$ Effective; 2 = Somewhat effective; 1 = Not effective $]$. In addition, the participants were asked to answer open-ended questions about their satisfaction with the strategy.

\section{Instructional Procedures for Teaching RAP Strategy}

In order to assess the effectiveness of the RAP paraphrasing strategy training, baseline, intervention, independent performance, maintenance and generalization probes were administered. The probes were developed as follows. The baseline probe data were collected simultaneously from all the participants and when stable data was obtained, the intervention was started with the first participant. After completing the training of the first participant, the independent performance probes were administered to all participants. In these probes, after stability was achieved with the second participant, the probes session was terminated and the training was started with the second participant. The independent performance probes were administered after the second participant's training was completed. In this session, stable data were achieved by the third participant, and then the third participant was trained. After the training of the third participant was completed, the last independent performance probes were administered. The maintenance probes were administered 2-weeks after the final independent performance probe and in addition generalization probes were administered 3-weeks after the end of the treatment.

A- Baseline. A minimum of three baseline probes were administered to each participant before beginning the treatment phase. In order to determine the baseline competence of the participants in using the steps in the RAP strategy, their baseline performance was investigated by determining the number of correct responses to the short-answer questions and the percentages with regard to text-recall. The baseline phase level lasted until each of the participant achieved stable sessions independently.

B- Treatment. After achieving a stable baseline, the first participant received the training until she/he reached the criterion level for independent performance. The criterion level for independent performance was that the participants were able to use the RAP steps while reading without any teacher support and answer reading comprehension questions. The criterion level was indicated by the participant' orally stating the main idea and details for each paragraph or by the participant' writing the main ideas and details for each paragraph using an RAP card without any assistance from the instructor. Once the criterion level was achieved, the participant then moved onto the independent performance phase, and the remaining participants were given the baseline probes. The same procedure was used for the remaining participants.

C- Independent performance. After the intervention phase was completed, four independent performance probes were given for each participant. These probes were administered under the same conditions as the baseline probes (Hagaman \& Reid, 2008). The participants did not receive any assistance nor did they receive any prompts or encouragement from the instructor or the observers during the probes.

$D$ - Maintenance. The maintenance probes were administered two weeks after the end of the independent performance to determine the permanency effect of the remained stable. The maintenance probes were administered in the same way as the baseline and independent practice probes.

E- Generalization. The generalization probes were administered to assess whether or not the participants were able to generalize the remained stable with regard to different reading materials. The generalization probes were administered in a different classroom under the same conditions as in the independent practice probes 3 weeks after the participants achieved the criterion-level in terms of the independent performance. The participants in the generalization probes were assessed with a variety of expository science texts at grade-level (Ministry of National Education, 2016b). They were asked to read the texts silently and then answer short-answer questions and to recall the main ideas and details in these texts.

\section{Treatment Fidelity and Reliability}

Two types of reliability measures were administered in this study. 
A- Inter-observer reliability. Inter-observer reliability is a comparison of assessments on the part of two independent observers working independently of each other but at the same time achieving target behavior. To collect the inter-observer reliability data, $40 \%$ of all sessions were collected and analyzed. The inter-observer reliability was calculated using the point-by points agreement "Reliability= Agreements / [Agreements + Disagreements] x 100" (Tekin-Iftar \& Kırcaali-Iftar, 2016) using the data collected by the investigator and the observers. The interobserver reliability was found to be $88 \%$ in the case of the probes and $90 \%$ in the intervention sessions

$B$ - Application reliability. A checklist was prepared by the investigator that contained the form of the RAP steps (see Figure 1) strategy training. To determine the reliability of the practice, the observers attended $40 \%$ of the intervention sessions and marked the items in the application reliability data checklist given to them. The reliability analysis of the application was used with the formula of "Observed practitioner behavior / Planned practitioner behavior x 100" (Billingsley, White \& Munson, 1980). The reliability of the application was found to vary between $88 \%$ and $94 \%$, with an average of $91 \%$.

\section{Intervention Practice Sessions}

Following the baseline probes, the RAP strategy training began with the first participant Murat. The form of the steps, as developed by Ellis et al. (1991) are associated with a modified version of the strategic instruction model and were provided through direct instruction to the participants during the intervention sessions. These were as follows:

1- Defining reading and reading comprehension. The instructor defines reading and reading comprehension concepts. The instructor gives an information about the importance of reading comprehension ability and its benefits. The instructor offers some case studies about what kinds of problems students who struggle with reading will encounter in the classrooms and social life.

2- Describing the RAP strategy. The instructor fully describes the RAP paraphrasing strategy and explains its steps. The instructor describes the acronyms of RAP and gives a RAP cards to the participant. The instructor paints a vivid picture with words to describe in details the use of the RAP strategy and its benefits in becoming more proficient in comprehending of what one reads in and out of school. The instructor also motivates the participant by stating that the he will be more successful at the end of the training and become an independent reader.

3- Modeling the strategy. This step was the practicing step of achieving stability in terms of the criterion level. The instructor performs the steps of RAP starting with the paraphrasing strategy for the participant using a thinkingaloud method in which he overtly verbalizes metacognitive statements (i.e., what do I need at the end of this reading?) and statements directly related to the cognitive strategy of the main idea selection (so far, this text seems to be about how to prepare for ... I will continue to read to infer if this is what it's really about). The instructor verbally, meta-cognitively and physically models the effective use of the strategy for the participant using an RAP card in classrooms prompting students to use the paraphrasing strategy. First, the instructor demonstrates how to use the RAP sections and identify the main idea by reading-aloud a paragraph in the text. After modeling, the participant reads a paragraph in an expository text and uses the RAP sections in Figure 1 (Harris \& Katims, 1997).

\begin{tabular}{|ll|}
\hline Step 1 & Read a paragraph \\
Step 2 & Ask yourself "What were the main idea and two details in this paragraph?" \\
\cline { 2 - 2 } & \\
Step 3 & Put the main idea and details into your own words \\
& \\
\hline
\end{tabular}

Figure 1. Steps for paraphrasing in the RAP strategy

4- Verbally elaborate and rehearse. After the modeling phase, the verbally rehearsing phase is begun. The instructor shows the RAP strategy with the participant using the text. The participant is asked to elaborate and rehearse verbally the three steps of the RAP strategy with $100 \%$ accuracy. After this step, the participant returns to the text and rehearses where to identify the main idea in the paragraph and to identify the key details and how to state the main and details using complete original sentences. The participant verbally rehearses this information and verbally elaborates the components of the strategy by associating them with other stages that he may have to use.
5- Practice acquisition. The participant engages in guided practice or practice acquisition of the RAP strategy using difficult expository texts. The instructor provides any support that is needed by modeling of the strategy and talking to the participant to improve his reading comprehension skills. This is done in order to enable the participant to acquire skills for paraphrasing the main ideas and details from the paragraphs that are relatively easy for him to read. To remind the participant about the use of the strategy, the instructor has already created a poster showing the RAP steps on a paragraph and hangs it on the wall of the classroom. The poster includes the main ideas of the paragraph and details and key words 
are repeated in the paragraph. When the participant is successful in using the RAP sections during the practice acquisition process, the instructor asks the participant to answer the reading comprehension questions by giving him a new text passage and a blank RAP card. The participant silently reads the passage and try to fill out the card. The instructor reviews the responses of the participant in the RAP card. When the participant responds correctly, the instructor gives a "+" for each question answered correctly on the prize board that has already been shown to the participant. After this process ends, the instructor checks the text paragraphs and responses with the participant and gives corrective feedback to the participant concerning his effective use of each step of the strategy.

6- Undertaking advanced practices for independent performance. The participant continues to use each step of the RAP, but advanced practice expository social studies grade-level texts. The instructor provides scaffolded and dialogic instruction as needed. The participant makes attempts to find the main idea and details until the participant achieves the level of independent performance in strategy acquisition under the guidance of the instructor. In addition, the participant interprets the target text by making dialogue and answering the comprehension questions about the text asked by the instructor. If there is a faulty in the trials, the instructor gives corrective feedbacks to the participant to identify the main idea and details. If there is still a problem, the instructor can return to the stage of practice acquisition. However, if the participant is able to use the three steps of the RAP with $100 \%$ accuracy, the participant is given independent performance probes.

\section{Data Analysis}

Five types of data were collected as part of this study: a) baseline, b) independent performance, c) maintenance, d) generalization and d) social validity. The collected data were analyzed graphically. The effect sizes for all participants were calculated using the "Nonoverlap of All Pairs" following guidelines developed by Parker, Vannest and Brown (2009). A nonoverlap of All Pairs [NAP] model is the percentage of non-coinciding data between the baseline phases and the intervention sessions. The difference between the curves on the graphic was interpreted to check whether or not the independent variable had an effect on the dependent variable. However, the social validity data were obtained from the self-report satisfaction form and were analyzed using the descriptive analysis method.

\section{Results}

Figure 2 showed the number of correct short-answer questions for all participants in terms of the baseline, independent performance, maintenance, and generalization probes. With regard the baseline data, the mean of the short-answer questions answered correctly by Murat, Mahmut and Vedat was 1.6/10, 1/10 and 1/10, respectively. After completion of the RAP training, the mean of the short-answer questions answered correctly by Murat, Mahmut and Vedat was 7.75/10, 6/10 and $8.75 / 10$, respectively in terms of the independent performance probes. Remarkably, Vedat showed greater improvement in his performance, than did the other participants from the baseline to the end of the training.

2-weeks follow up; the maintenance probes were administered under the same conditions as the baseline probes to investigate the permanent effect of the strategic training on the participants. In terms of maintenance, the mean number of correct responses for Murat, Mahmut and Vedat were 8.5/10, 5.5/10 and 8/10, respectively. Compared to the baseline data, the performance of Murat and Vedat remained stable (the goal criteria is the "RAP" paraphrasing strategy) in the maintenance probes after the end of the training. Vedat retained his goal-setting at a high-level after the completion of the strategy. However, a decrease in Mahmut's performance was identified in terms of the maintenance probes. These results indicated that Mahmut was unable to achieve his goal-setting. The goalsetting target met when the participants could correctly use each of the "RAP" steps without support from the instructor and answer the short-answer questions correctly.

At the 3-week follow up, the generalization probes were administered. The mean number of short-answer questions answered correctly by Murat, Mahmut and Vedat were 7.5/10, 5/10 and 7.75/10, respectively. According to these results, Murat showed that he could generalize his performance to the expository science texts, but Mahmut was unable to generalize his strategy to the science texts. Vedat was able to generalize to the science texts. There participants showed significant improvements in their reading comprehension skills using the RAP paraphrasing strategy from the baseline to the independent performance. However, when the maintenance probes were administered 2-week follow-up after the end of independent performance, Murat and Vedat reached the criterion level, while a significantly decline in Mahmut's performance was observed. The criterion-level was defined as independently reading a passage while using the "RAP" strategy (writing the main idea and details for each paragraph in a text) without any help from the instructor (Hagaman \& Reid, 2008). When the generalization probes were examined, Murat and Vedat accomplished the goal by generalizing to different content-area texts. However, Mahmut could not generalize the RAP strategy to the science texts. The results for Murat and Vedat suggested the possibility that readers at frustration-level reading could generalize a paraphrasing strategy to different reading materials as a result of the strategic instruction training. The effect sizes for Murat, Mahmut and Vedat were .87, 82 and 94, respectively. These results indicated moderate to strong effects of the strategic instruction for all the participants. 


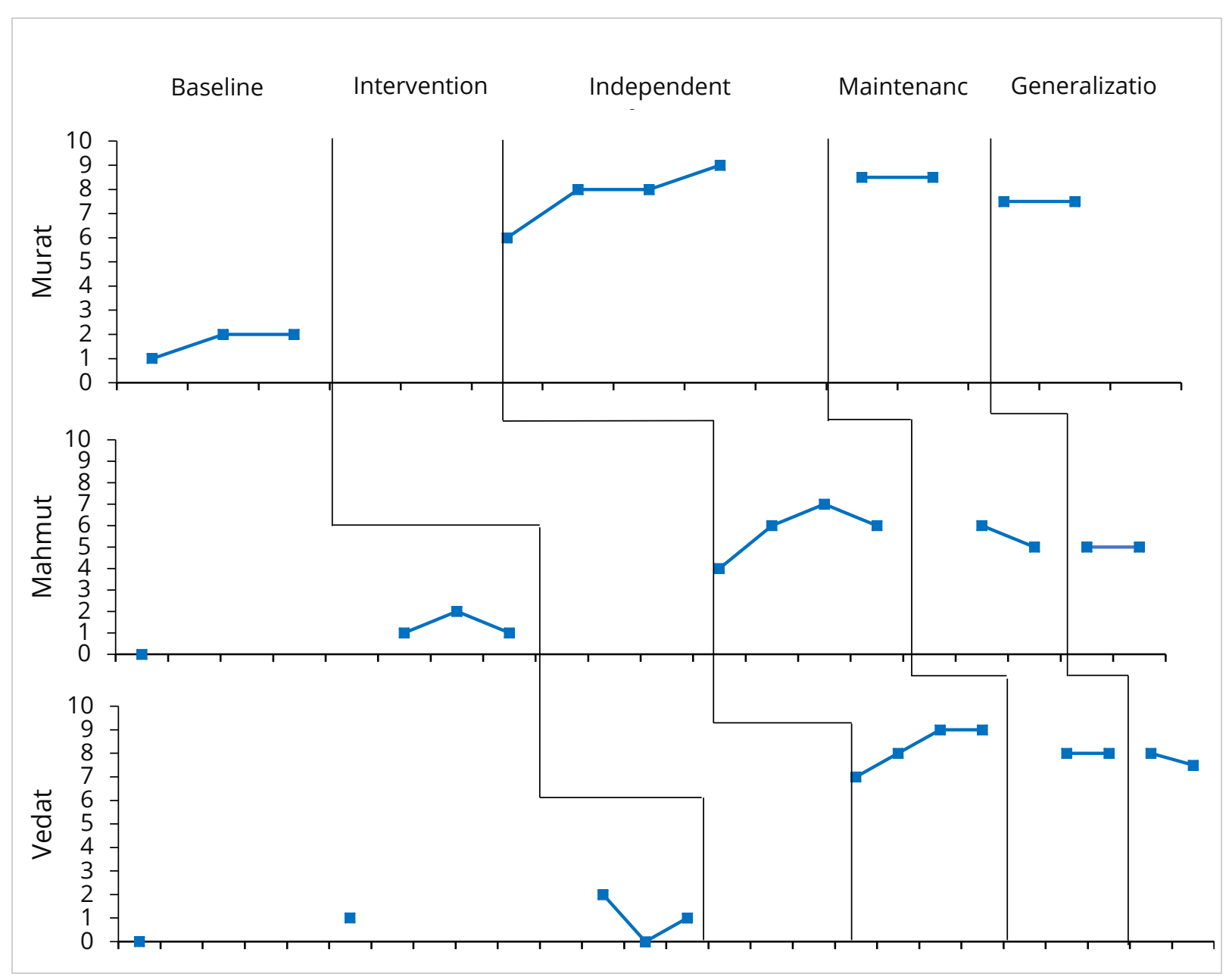

Figure 2. The Number of the Correct Short-Answer Questions of the Participants

The percentages of the text recall on the part each of participant was presented in Figure 3. With regard to the baseline phase probes, it was found that all the participants showed poor performance in their text-recall percentage scores. For Murat, Mahmut and Vedat, the mean percentages of the text-recall in the baseline was $17.6 \%, 13 \%$ and $14 \%$, respectively. This result indicated that all participants were low for both main ideas and details in expository texts. The baseline probes remained stable and low levels for all the participants. However, the performance in the text-recall percentages increased immediately for all participants following the training. For Murat, Mahmut and Vedat, the mean percentage of textrecall scores during the independent performance probes was $77.5 \%, 65 \%$ and $80 \%$, respectively. The percentage increase for Murat, Mahmut and Vedat was 340\%, 400\%, and $471 \%$, respectively. When the distributions percentage increase in terms of the text-recall for all participants were examined, Vedat showed the greatest improvement again as in the short-answer questions. However, the treatment effects were maintained 2-weeks after the intervention sessions. For Murat and Vedat, the mean percentage of text-recall from the maintenance probes were $85 \%$ and $87.5 \%$, respectively. In contrast, for Mahmut it was $62.5 \%$. Mahmut did not maintain his goal in the 2-week follow up. Nonetheless he made more

remarkably increased improvement over his baseline level as a result of the intervention.

Furthermore, 3-weeks after the strategy training the generalization probes were administered to determine whether or not any participants generalized their performance to the expository science texts at gradelevel. The mean percentage of the text-recall in the generalization probes for Murat, Mahmut and Vedat was $77.5 \%, 57.5 \%$ and $85 \%$, respectively. This finding indicated that with the exception of Mahmut, the other participants could generalize their paraphrasing strategy to different types of texts. Mahmut increased the mean percentage of text-recall in the independent performance probes by a factor of approximately 5 compared to the baseline probes. In contrast, Mahmut's performance was reduced in the maintenance probe and he was not able to maintain his achievement. For all participants, the NAP was $.94, .78$ and .91 , respectively indicating medium effects. 


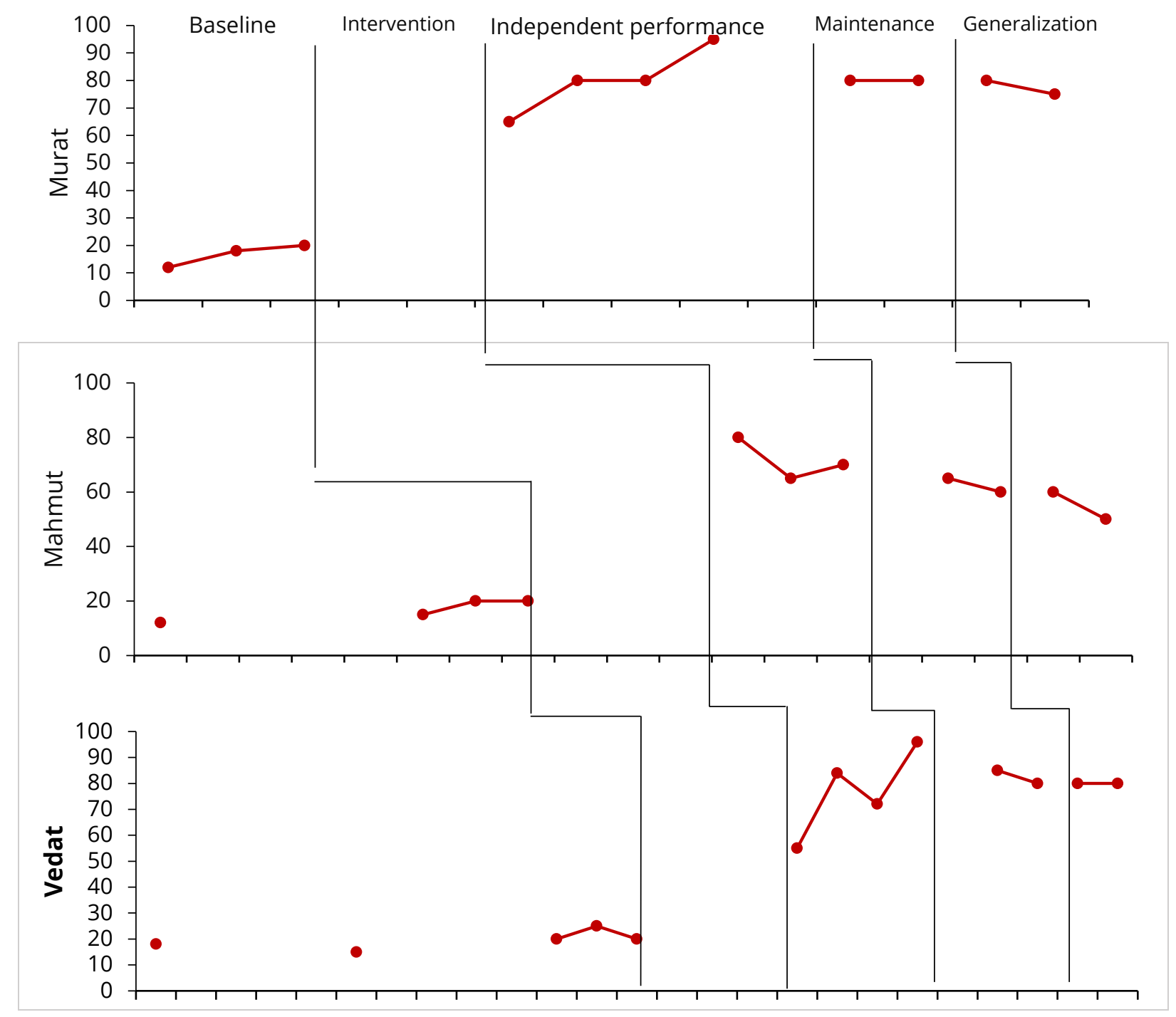

Figure 3. Percentages of Text Recall (Main ideas \& Details) of the Participants

\section{Social Validity Results}

The social validity results showed that the teaching of the RAP strategy had a positive effect on the participants. The participants stated that they liked the RAP strategy training and felt that it would help them understand any reading material. When the participants were asked whether or not they would recommend the RAP strategy to other in the class, different answers were found. For instance, two of the participant reported strongly that they would recommend the sections in the RAP to their classmates; in contrast, one participant stated that he was not completely sure about it. The rating of the benefits of the strategy ( 1 to 5 ) for Murat, Mahmut and Vedat averaged 3.9, 2.7, and 4.5, respectively. When asked to share their satisfaction with regard to the steps of the paraphrasing strategy training, two of the participants commented that they liked the RAP cards. The participants also talked about a range of reading outcomes within the strategy training, such as main ideas and identifying details that were located within the passage, dialogue with themselves during reading texts and how to generate correct paraphrases. The participants thought that the use of the RAP sections involved calling upon them to recite their individual paraphrases of different parts of the passages. Lastly, when asked what they liked least, one participant commented that some of the social studies texts were difficult and complex to read comprehension, and it was difficult to identify the main ideas and many of the details in these texts due to a series of technical vocabulary words, and concepts. One participant stated that he did 
not like to write details in the text recall activities, but instead preferred to state the main idea and details orally.

\section{Discussion}

The effectiveness of the RAP paraphrasing strategy was investigated with regard to the development of reading comprehension on the part of frustration-level readers in this study. In addition, a self-report satisfaction form was used to determine the social validity of the strategy training. The results showed that all the participants achieved the criteria level after the strategy instruction. All the participants showed significant improvements in their reading comprehension. For instance, while Murat's performance was $16 \%$ on the baseline, his score was $77.5 \%$ at the end of the independence performance. In the 2-weeks follow-up after the end of the instruction, in term of the maintenance probes, Murat managed to maintain the goal-setting (i.e. the RAP paraphrasing skill acquisition) with a score of $8.25 / 10$ in the short-answer question test. When the result for Mahmut was examined, the mean of the correct responses to the short-answer questions in the baseline phase was 1/10; whereas this score increased to $5.25 / 10$ in the independent performance. However, there was a decline in the percentages associated with Mahmut's correct answers to the short-answer questions in terms of the maintenance probes. Mahmut nevertheless made more significant improvements compared with the baseline. Lastly, Vedat showed a marked increase in the mean of the correct answers to the short-answer questions from the baseline to the maintenance probes. Vedat's results maintained progress and remained above the baseline performance.

The findings confirmed that the paraphrasing strategy training with regard to reading improved the students ability to answer comprehension questions about the materials. The results suggested that the more paraphrasing a student did, the higher was her/his reading comprehension score (Schumaker et al. 1984 citied Katims \& Harris, 1997). In the generalization probes, only Murat and Vedat were able to generalize the RAP paraphrasing strategy they acquired in the independent performance to the science texts. Mahmut had a problem when it came to generalizing the strategy to the science texts in terms of the generalization probes. This finding confirms that the use of a paraphrasing strategy, associated with the self-regulated strategic instruction model, can influence understanding as to how readers construct a representation of incoming information (Katims \& Harris, 1997). However, the effectiveness of the comprehension enhancement strategy training, RAP, was investigated in terms of assessment of the participants' text recall of expository texts. As in the results of the cloze test scores, once again the mean percentage with regard to the text-recall on the part of the participants confirmed that they were at a frustration-level in terms of reading comprehension. This is because in the baseline probes, the participants' performance was low in terms of the main ideas and details in the expository texts. Achieving stable data from the independent performance and the maintenance probes indicated that the cognitive strategy training had a strong effect on the participants' main idea and details recall (in mean percentages). All the participants increased the percentage of recall the main idea and detail in the texts in the independent performance. The percentage increase for the participants was $431 \%, 223 \%$ and $291 \%$, respectively. In the independent performance phase, Murat and Vedat showed the greatest gains in the percentage of the main ideas and details recall, as well as the mean number of correct responses to the short-answer reading comprehension questions. It seems the paraphrasing strategy training aimed at improving reading comprehension skills was a fairly effective procedure for Murat and Vedat. In terms of the participants' results in the maintenance probes, the performance of Murat and Vedat was $82.5 \%$ and $80 \%$, respectively. Murat and Vedat reached the criterion level and so exhibited a marked improvement that remained well above the baseline during the maintenance. However, in contrast it was found that Mahmut's text recall percentage decreased from the independent performance to the maintenance phase. Mahmut did not meet his goal in the 2-weeks follow up with regard to the final independent performance probe. Finally, the generalization results suggested that the participants at a frustration-level in terms of reading comprehension generalized their paraphrasing strategy performance to other settings. This can be seen because in the generalization probes, Murat and Vedat began to master each step of the strategy in the "RAP" in the science texts.

Previous studies investigating the effects of teaching cognitive strategies to students have shown that this types of awareness facilitated and supported reading comprehension on the part of both average and lowachieving students (Palincsar \& Brown, 1985). Previous studies have showed that the RAP strategy which required paraphrasing and main idea summarizing skills increased effectively students' comprehension of main ideas and details of expository texts (Hagaman et al., 2016; Lauterbach \& Bender, 1995; Lee, \& Von-Colln, 2003; Ozdemir, 2015). For instance, Ellis and Graves (1990) found the paraphrasing instruction was superior to the repeated readings procedures on the reading comprehension of main ideas. Hagaman et al. (2012) investigated the effects of the RAP strategy training on the understanding of expository texts for six third-grade students identified as fluent readers who experienced difficulty with comprehension. Results showed that paraphrasing strategy training increased reading comprehension as measured by the short-answer questions and the percentage of text recall.

Hagaman, Luschen and Reid (2010) underlined the acronyms in RAP. This is because paraphrasing is a strategic meta-cognitive process that requires students to actively construct new meanings from text prompting students to use their complete, original sentences and summarization skills. The RAP acronyms are taught to students in order to activate their inner, cognitive dialogues, and to make them think about and actively apply the steps in a particular strategy. Hence acronyms serve such a purpose and help remind readers who use the RAP strategy to talk to themselves as a way of improving their reading comprehension (Katims \& Harris, 1997). The social validity results confirmed the practical 
usefulness of the cognitive strategy training in the enhancement of understanding textual information on the part of the participants. The students responded positively during the interview following the study. Two of the participants who responded best to the intervention rated it highest in terms of the effectiveness and application. In contrast, the participant who responded least well overall gave it the lowest ratings with regard to effectiveness.

In sum, through the metacognitive interventions in this study students with difficulties in reading development used processing RAP paraphrasing strategy to promote their active reading engagement with text materials (Loxterman, Beck \& McKeown, 1994). All findings have important theoretical and practical implications with respect to reading assessment for students at different reading ability levels.

\section{Limitations}

As with all studies, this study was not without a number of limitations that should be addressed by future researchers. First, a multiple-probe design across participants was used to investigate the effects of the strategic training on reading. The sample used in this study was limited to only four fourth-grade participants. In order to generalize the results of the study, future research should replicate these findings across diverse populations. Secondly, only the cloze test procedure which involved one of the informal reading inventories and teacher interviews were used in the determination of the reading comprehension level of the participants in order to identify whether or not the participants were at a frustration-level in terms of reading comprehension. Thirdly, this study did not address all participants' reading performance in terms of word recognition, word reading accuracy and reading fluency measures. Future research should replicate the study using reading performance measures involving an informal reading inventory including these types of variables. Fourthly, the period maintenance probe was administered shortly after the intervention (2-weeks after the final independent performance) and only the two maintenance measures were administered. It does not seem possible to observe benefits in terms of the participants' goals in the longterm from this study. Long-term maintenance is a concern for readers who struggle when it comes to reading (Hagaman \& Reid, 2008). Future research should investigate the effects of the use of delayed maintenance probes. Fifthly, the RAP strategy instruction was carried out on a one-to-one basis with the three participants. Future research should determine whether such an intervention would be equally effective in small-group or whole-class settings. Sixthly, all texts in this study consisted of expository text passages that were used in all the probes and in the intervention sessions in order to investigate the effects of the RAP strategy on the development of the participants' reading comprehension. Williams (2005) points out that it is important that we should consider the understanding of expository texts. As previously mentioned in this paper, reading comprehension expository texts for poor readers is more difficult than reading comprehension with regard to narrative texts. Future research should investigate the effects of paraphrasing strategy on narrative texts as a means of assessing the comprehension performance of poor readers. Seventhly, the generalization probes were administered to determine whether or not the participants would use the strategy that, they had learned in the independent performance dealing with different types of texts (e.g. social studies and science). For this reason, the expository science texts were used at gradelevel in the generalization probes. Future research should address generalize probes that determined whether or not any participants can use their performance skills in other settings or in real-word classrooms. Future research is needed with regard to students reading comprehension skills to enhance the generalizability of the RAP paraphrasing strategy.

\section{Conclusions}

All results indicated that teaching a cognitively-based paraphrasing strategy taught using the self-regulated model was effective in enhancing the comprehension of frustration-level readers. The findings suggest the usefulness such a strategy in addressing reading comprehension difficulties and problems in general education classrooms (Lee \& Von-Colln 2003). This is because in a relatively short-period of time, the participants' comprehension increased as measured by both the short-answer questions and the text-recall percentages. It was found that the criterion levels were met for three participants in the independent performance probes. Findings suggest that the paraphrasing strategy could be incorporated and adapted to content-area curriculum in the form of targeted support for students who were at a frustration-level reading in terms of their understanding and recall of main ideas and details in expository texts. In particular, content-area teachers such as social studies teachers whose work is heavily text-based and requires advanced critical literacy skills (Monte-Sano, 2011), can be responsible for the continued use of the reading comprehension strategy to overcome their students' difficulties with regard to content-area readings. The ability to glean meaning from expository texts is probably one of the most important skills for success in presentday schools (Harris \& Katims, 1997). The findings of this paper were unique in terms of students at frustrationlevel reading. RAP strategy training appears to be of value for students with difficulties in reading. Because intervention sessions take a very short time, the use of RAP sections can be practical can lead to positive outcomes related to students' reading achievement. In addition, content-area teachers can use RAP for those students who struggle in cognition areas, such as main idea comprehension, inferences, paraphrasing, problem solving, and distinguishing relevant from irrelevant information in their content-area instruction. A challenge for teachers who attempts to use cognitive strategy training is the appropriate selection of reading materials for teaching RAP strategy. Teachers can wish to vary difficult expository texts they use to teach their students the RAP procedure in order to verify the benefits of using the strategy. Accordingly, teaching students strategyoriented approaches seems useful for developing their 
reading comprehension skills and for their overall reading success.

\section{References}

Akyol, H. (2011). Türkçe öğretim yöntemleri. Ankara: Pegem Akademi Yayıncılık

Alfassi, M. (2004). Reading to learn: Effects of combined strategy instruction on high-school students. Journal of Educational Research, 97, 171-184

Berkeley, S. (2007). Reading comprehension instruction for students with learning disabilities. In T. E. Scruggs \& M. A. Mastropieri (Eds.), Advances in learning and behavioral disabilities: Vol. 20, International perspectives (pp. 79-99). Oxford, UK: Elsevier

Best, R. M., Rowe, M., Ozuru, Y., \& McNamara, D. S. (2005). Deep-level comprehension of science texts: The role of the reader and the text. Topics in Language Disorders, 25, 65-83

Biancarosa, C., \& Snow, C. E. (2006). Reading next: A vision for action and research in middle and high-school literacy. A report to Carnegie Corporation of New York (2nd ed.). Washington, DC: Alliance for Excellent Education.

Billingsley, F., White, O. R., Munson, R. (1980). Procedural reliability: A rationale and an example. Behavioral Assessment, 2, 229-241

Cavkaytar, S. (2010). illköğretimde yazııı anlatım becerilerinin geliştirilmesinde yazma süreci modelinden yararlanma. Journal of International Social Research, 3(10), 133-139

Dağ, N. (2010). Okuma güçlügü̈nün giderilmesinde 3P metodu ile boşluk tamamlama (Cloze) tekniğinin kullanımı üzerine bir çalışma. Ankara Üniversitesi Eğitim Bilimleri Fakültesi Özel Eğitim Dergisi, 11(1), 63-74

Deshler, D. D., \& Lenz, B.K. (1989). The strategies instructional approach. International journal of Disability, Development, and Education, 36, 203-224

Dickens, R. H., \& Meisinger, E. B. (2016). Examining the effects of skill level and reading modality on reading comprehension. Reading Psychology, 37(2), 318-337

Ellis, E. S., \& Graves, A. W. (1990). Teaching rural students with learning disabilities: A paraphrasing strategy to increase comprehension of main ideas. Rural Special Education Quarterly, 10(2), 2-10

Fordham, N. W., Wellman, D., \& Sandmann, A. (2002). Taming the text: Engaging and supporting students in social studies readings. Social Studies, 93,149-159

Gickling, E. E. \& Thompson, V. P. (1985). A personal view of curriculum-based assessment. Exceptional Children, $52,205-218$

Grant, P. (1978). Using the cloze procedure as an instructional device: What the literature says. Paper presented at the 23rd Annual Convention of the International Reading Association, Houston, TX.
Hagaman, J. L., \& Reid, R. (2008). The effects of the paraphrasing strategy on the reading comprehension of middle school students at risk for failure in reading. Remedial and Special Education, 29, 222-234

Hagaman, J. L., Casey, K. J., \& Reid, R. (2012). The effects of the paraphrasing strategy on the reading comprehension of young students. Remedial and Special Education, 33(2), 110-123

Hagaman, J. L., Casey, K. J., \& Reid, R. (2016). Paraphrasing strategy instruction for struggling readers: Preventing school failure. Alternative Education for Children and Youth, 60(1), 43-52

Hagaman, J. L., Luschen, K. \& Reid. R. (2010). The RAP on reading comprehension. Teaching Exceptional Children, 43(1), 22-29

Halladay, J. L. (2012). Revisiting key assumptions of the reading level framework. The Reading Teacher, 66(1), 53-62

Ilter, I. (2017). Teaching word meanings to students at different reading ability: A controlled assessment of the contextual-based vocabulary instruction on reading comprehension. Education and Science, 42(190), 437-463

Jennings, J. H., Caldwell, J., \& Lerner, J. W. (2006). Reading problems: Assessment and teaching strategies (5th ed). Boston, MA: Pearson Education

Katims, D. S., \& Harris, S. (1997). Improving the reading comprehension of middle-school students in inclusive classrooms. Journal of Adolescent and Adult Literacy, 41, 116-123

Kletzien, S. B. (2009). Paraphrasing: An effective comprehension strategy. The Reading Teacher, 63(1), 73-77

Kuhn, M., \& Stalh, A. (1998). Teaching children to learn word meanings from context: A synthesis and some questions. Journal of Literacy Research, 30(1), 119-138

Kurt, B. (2016). Climate change. TUBITAK Science Books, 39 Ankara: Nurol Matbaacılık

Lauterbach, S.L. \& Bender, W.N. (1995). Cognitive strategy Instruction for reading comprehension: a success for high-school freshman. The High School Journal. 79, 5864

Lee, S. W., \& Von-Colln, T. (2003). The effect of instruction in the paraphrasing strategy on reading fluency and comprehension. (ERIC Number: ED476287)

Leslie, L., \& Caldwell, J. A. (2011). Qualitative Reading Inventory (5th ed.). Boston, MA: Pearson Education.

Loxterman, J. A., Beck, I. L., \& McKeown, M. G. (1994). The effects of thinking aloud during reading on students' comprehension of more or less coherent text. Reading Research Quarterly, 29(4), 353-367.

Macdonald-Ross, M., \& Scott, B. (1995). Results of the survey of OU students' reading skills. Text and Readers Programme: Technical Report 3, Milton 
Keynes: Institute of Educational Technology, Open University

Mastropieri, M. A., Scruggs, T. E., \& Graetz, J. E. (2003). Reading comprehension instruction for secondary students: Challenges for struggling students and teachers. Learning Disability Quarterly, 26, 103-116

McGuire, B. (2013). Natural disasters (Trans. Said Vapur). TUBITAK Science Books, 442 Ankara: Nurol Matbaacılık

McKenna, M. C., \& Stahl, K. A. D. (2009). Assessment for reading instruction. Guilford Publications

McLeod, J., \& Anderson, J. (1970). An approach to assessment of reading ability through information transmission. Journal of Reading Behavior, 2, 116-143.

Miles, M. B., \& Huberman, A. M. (1994). Qualitative data analysis: An expanded sourcebook (2 ed. J. Beverly Hills, CA: Sage

Ministry of National Education. (2016a). Sosyal Bilgiler - 4 Ders ve Öğrenci Çalışma Kitabı. Ankara: Koza Yayınları

Ministry of National Education. (2016b). Ilkokul Fen Bilimleri 4. sınıf Ders Kitabı (1. ve 2. Kitap). Ankara: MEB Yayınları Ders Kitapları Dizisi

Monte-Sano, C. (2011). Beyond reading comprehension and summary: Learning to read and write in history by focusing on evidence, perspective, and interpretation. Curriculum Inquiry, 41(2), 212-249.

Oxford, R. L. (1990). Language Learning Strategies: What every teacher should know. Boston: Heinle \& Heinle

Özdemir, i. (2015). Açımlama stratejisi öğretiminin öğrencilerin okuduğunu anlama becerilerine etkisi. Turkish Journal, 1(2), 1-11

Palincsar, A.S., \& Brown, A.L. (1985). Reciprocal teaching of comprehension-fostering and comprehensionmonitoring activities. Cognition and Instruction, 1(1), $17-175$

Palumbo, A., \& Loiacono, V. (2009). Understanding the causes of intermediate and middle school comprehension problems. International Journal of Special Education, 24(1), 75-81

Parker, R. I., Vannest, K. J., \& Brown, L. (2009). The improvement rate difference for single case research. Exceptional Children, 75, 135-150

Pressley, M. (2002). Reading instruction that works: The case for balanced teaching (2nd ed.). New York: Guildford Press

Pressley, M., \& McCormick, C. (1995). Advanced educational psychology. New York: Harcourt Brace

Rachel, H. Dickens \& Elizabeth B. Meisinger (2017). Examining the effects of reading modality and passage genre on reading comprehension in middle school students. Reading Psychology, 38(3), 321-347
Rasinski, T. (1999). Exploring a method for estimating independent, instructional and frustration reading rates. Reading Psychology, 20, 61-69

Rasinski, T. (2006). Reading fluency instruction: Moving beyond accuracy, automaticity, and prosody. The Reading Teacher, 59(7), 704-706

Rasinski, T. (2012). Why reading fluency should be hot! The Reading Teacher, 65 (8), 516-522

Reid, R., Lienemann, T. O., \& Hagaman, J. L. (2013). Strategy instruction for students with learning disabilities. New York, NY: Guilford Press

Rosenshine, B., Meister, C. \& Chapman, S. (1996). Teaching students to generate questions: A review of the intervention studies. Review of Educational Research, 66(2), 181-221

Rubin, J. (2011). Organizing and evaluating results from multiple reading assessments. The Reading Teacher, 64(8), 606-611

Şahindokuyucu, A. (2006). A study of cloze and multiplechoice tests for measuring reading comprehension of preparatory students. (Unpublished master's thesis). Bolu Abant Izzet Baysal University

Schumaker, J.B., Deshler, D.D., \& Ellis, E.S. (1986). Intervention issues related to the education of LD adolescents. In J.K. Torgeson \& B.Y.L. Wong (Eds.), Learning disabilities: Some new perspectives. New York: Academic Press.

Shanahan, T., \& Shanahan, C. (2008). Teaching disciplinary literacy to adolescents: Rethinking content-area literacy. Harvard Educational Review, 78(1), 40-59

Smagorinsky, P. (2001). If meaning is constructed what's it made from? Toward a cultural theory of reading. Review of Educational Research, 71, 133-169

Snyder, B., \& Pressley, M. (1995). Introduction to cognitive strategy instruction. In M. Pressley \& V. Woloshyn (Eds.), Cognitive strategy instruction that really improves children's academic performance (pp. 1-18). Cambridge, MA: Brookline

Taraban, R., Rynearson, K. \& Kerr, M. (2000). College students' academıc performance and self-reports of comprehension strategy use. Reading Psychology, 21(4), 283-308

Tekin-iftar, E. \& Kırcaali-iftar, G. (2016). Özel eğitimde yanlışsız öğretim yöntemleri. Ankara: Nobel Yayın Dağıtım

Tomesen, M., \& Aarnoutse, C. (1998). Effects of an instructional programme for deriving word meanings 1. Educational Studies, 24(1), 107-128

Toste, J. R., Fuchs, D., \& Fuchs, L. S. (2013). Supporting struggling readers in high school. In R. T. Boon \& V. G. Spencer (Eds.), Adolescent literacy (pp. 79-91). Baltimore, MD: Brookes

Ulusoy, M. (2009). Using cloze test to measure students' reading levels and readability of texts. Journal of Turkish Educational Sciences, 7(1), 105-126 
Ulusoy, M., \& Dedeoğlu, H. (2011). Content-area reading and writing: Practices and beliefs. Australian Journal of Teacher Education, 36(4), 1-17

Vacca, R. T., Vacca, J. L., \& Mraz, M. E. (2011). Content-area reading: Literacy and learning across the curriculum (10th ed.). Boston, MA: Allyn \& Bacon

Vacca, R.T., \& Vacca, J.L. (2008). Content-area reading: Literacy and learning across the curriculum (9th ed. pp. 56-59). Boston: Allyn \& Bacon

Van-Den Broek, P., Kendeou, P., Lousberg, S., \& Visser, G. (2011). Preparing for reading comprehension: Fostering text comprehension skills in preschool and early elementary school children. International Electronic Journal of Elementary Education, 4(1), 259-268

Vassaf, B. H. (2003). Öğrenme yetersizliği. Ankara: Milli Eğitim Bakanlığı Yayınları

Watson, S. M. R., Gable, R. A., Gear, S. B., \& Hughes, K. C. (2012). Evidence-based strategies for improving the reading comprehension of secondary students: Implications for students with learning disabilities. Learning Disabilities Research \& Practice, 27, 79-89

Westfall, R. S. (2005). Story of energy (7. ed.) (Trans. Tüysüzoğlu, B. B). TUBITAK Science Books, 86, Ankara: Nurol Matbaacılık
Williams, J. P. (2002). Reading comprehension strategies and teacher preparation. In A. Farstrup \& J. Samuels (Eds.), What research has to say about reading instruction (3rd ed., pp. 243-260). Newark, DE: International Reading Association

Williams, J. P. (2005). Instruction in reading comprehension for primary-grade students: A focus on text structure. Journal of Special Education, 39, 6-18

Wolf, M. M. (1978). Social validity: The case for subjective measurement or how applied behavior analysis is finding its heart. Journal of applied behavior analysis, 11(2), 203-214

Worthy, J., \& Broaddus, K. (2001). Fluency beyond the primary grades: From group performance to silent, independent reading. The Reading Teacher, 55(4), 334343

Zutell, J., \& Rasinski, T. V. (1991). Training teachers to attend to their students' oral reading fluency. Theory into Practice, 30(3), 211-217 